\title{
Removal of phosphate from aqueous solution by red mud using a factorial design
}

\author{
Ying Zhao, Jun Wang, Zhaokun Luan*, Xianjia Peng, Zhen Liang, Li Shi \\ State Key Laboratory of Environmental Aquatic Chemistry, Research Center for Eco-Environmental Sciences, Chinese Academy of Sciences,
} P.O. Box 2871, Beijing 100085, PR China

\section{A R T I C L E I N F O}

\section{Article history:}

Received 22 June 2008

Received in revised form 26 October 2008

Accepted 30 October 2008

Available online 5 November 2008

\section{Keywords:}

Phosphate removal

Red mud

Sorption

Factorial design

\begin{abstract}
A B S T R A C T
The purpose of the work is to study the adsorption of phosphate on red mud from aqueous solutions using $2^{3}$ full factorial designs. The important parameters, which affect the removal efficiency of phosphate and final $\mathrm{pH}$ of solution $\left(\mathrm{pH}_{\mathrm{f}}\right)$, such as phosphate concentration, initial $\mathrm{pH}$ of solution $\left(\mathrm{pH}_{\mathrm{i}}\right)$ and the red mud dosage were investigated. The effects of individual variables and their interaction effects for dependent variables, namely, phosphate removal efficiency and $\mathrm{pH}_{\mathrm{f}}$ were determined. The results of the study showed that phosphate removal efficiency and $\mathrm{pH}_{\mathrm{f}}$ were found to be $97.6 \%$ and 10.9 with optimal reaction conditions initial phosphate concentration $25 \mathrm{mgl}^{-1}$, red mud dosage $1.5 \mathrm{gl}^{-1}$, $\mathrm{pH}_{\mathrm{i}} 3.0$, respectively. It was found that adequate amount of calcium ions and higher final $\mathrm{pH}$ than 9 are ideal conditions for maximum phosphate removal.
\end{abstract}

(c) 2008 Published by Elsevier B.V.

\section{Introduction}

Phosphate in wastewaters is an essential nutrient for the growth of photosynthetic algae and other biological organisms in water bodies. But excess phosphate concentration in the effluent discharge can lead to eutrophication of the receiving confined water bodies [1]. Eutrophication can in turn disturb the balance of organisms present in the water and affect water quality, mainly through oxygen depletion as the algae decay. A reduced oxygen level harmfully affects fish and other aquatic life, microorganism and insects' growth as well as it causes natural resorts degradation. Consequently, the amount of phosphate in domestic and industrial discharges must be controlled using wastewater treatment technology.

In wastewater treatment technology, many methods have been developed for phosphate removal [2], which include physical [3], chemical [4] and biological methods [5]. Physical methods have proved to be either too expensive, as in the case of electrodialysis and reverse osmosis [3], or inefficient, removing only $10 \%$ of the total phosphorus [4]. Enhanced biological treatment can remove up to $97 \%$ of the total phosphorus and it is low-cost. But the variability in chemical composition and temperature of wastewater would make the implementation of this process not

\footnotetext{
* Corresponding author. Tel.: +86 1062849150 ; fax: +86 1062849198.

E-mail addresses: zhao_ying005@yahoo.com.cn (Y. Zhao), Luanzk@rcees.ac.cn (Z. Luan).
}

feasible for wastewater treatment [5]. Chemical removal techniques are the most effective and well-established methods up to date. Lime, aluminum sulfate, and ferric chloride are common precipitants used for phosphate removal [2]. However, the cost associated with the use of metal salts and sludge production may hinder the widespread application [6]. Therefore, alternative techniques for phosphate removal are being developed. Recently, attention has been focused on phosphate adsorbents because of the most economical and applicable of adsorption. Successful results have been obtained using fly ash [5,7,15], aluminum oxide [8-10], iron oxide [11-14], slag [16,17], red mud $[18,19]$, silicates $[20,21]$, activated carbon [22], and gas concrete [23].

Red mud emerges as a residue during alkaline-leaching of bauxite in Bayer process. Roughly 1-2 tons of red mud residue are produced for a ton of alumina [24]. About 10-20 million tons of caustic red mud must be disposed of annually in China during recent years [25]. Since the plant began to process, red mud has accumulated over years and causes a serious environmental problem due to its high alkalinity and large amount.

Many have studied the application of red mud in wastewater treatment and red mud has been found to remove fluoride [26], chromium [27], hexavalent [28], dyes [29], heavy metals [30], and phosphate $[5,31]$ from aqueous solution. Due to the high percentages of calcium, aluminum and iron, red mud is a good candidate for use as an economic adsorbent for large-scale use. In this study, phosphate was removed using original red mud. One of the main advantages of phosphate removal by using red mud over the other 
chemical treatment is the abundance of red mud and its easy availability.

Many previous studies showed that phosphate precipitates with calcium as apatites and especially hydroxyapatites (HAP). Because the extent of HAP formation is critically dependent on factors such as degree of supersaturation, $\mathrm{pH}$ and initial phosphate concentration $[32,33]$, it is necessary to study the effect of red mud dosage, initial $\mathrm{pH}$ of solution $\left(\mathrm{pH}_{\mathrm{i}}\right)$ and phosphate concentration on the final $\mathrm{pH}\left(\mathrm{pH}_{\mathrm{f}}\right)$ which directly affects the formation of HAP.

This study examined the effect of original red mud on phosphate removal. The influence of phosphate concentration, $\mathrm{pH}_{\mathrm{i}}$ and red mud dosage on the removal efficiency of phosphate using experimental design methodology was investigated. The main effects and their interactions of the parameters considered were studied by using a $2^{3}$ factorial design.

\section{Materials and methods}

\subsection{Materials}

The red mud used in this study was obtained from Shandong Aluminium Corporation, Shandong, China. Before batch experiments were performed the red mud was first sieved and the particles smaller than 100 mesh were kept for further consideration in the trials without any further treatment. The average chemical composition of red mud was listed in Table 1 . This table showed that red mud is primarily a mixture of $\mathrm{Ca}, \mathrm{Si}, \mathrm{Fe}$ and $\mathrm{Al}$ oxides and the $\mathrm{CaO}$ content is the highest. The single-point $\mathrm{N}_{2}$-BET method indicated that the specific surface area of a typical red mud sample was about $14.76 \mathrm{~m}^{2} / \mathrm{g}$.

The standard phosphate solutions used in the experiments were prepared from a stock solution of $1 \mathrm{~g} \mathrm{Pl}^{-1}$ anhydrous $\mathrm{KH}_{2} \mathrm{PO}_{4}$. The determination of phosphate has been measured using the ascorbic acid method with a HACH DR/4000U spectrophotometer, according to APHA standard methods [34]. A pH meter (Orion) was used to measure the $\mathrm{pH}$ of solutions in experiments and $\mathrm{pH}$ adjustments of solutions have been done by diluted $\mathrm{HCl}$ and $\mathrm{NaOH}$. The chemicals used for this study were analytical reagent-grade or better and all experiments were conducted in duplicate and the average values were used for analysis.

\subsection{Experimental procedure}

In order to determine phosphate removal capacity and effect on $\mathrm{pH}_{\mathrm{f}}$ of the red mud, batch experiments were conducted. The experimental procedure was as follows: a defined volume of the phosphate stock solution with a concentration $1 \mathrm{~g} \mathrm{Pl}^{-1}$ in $\mathrm{PO}_{4}{ }^{3-}$ was diluted to the experimental concentration by adding tap water of very low hardness. The $\mathrm{pH}$ of the solution was then adjusted to the desired value and a defined amount of adsorbent was added. The mixture was stirred at $200 \mathrm{rpm}$ at room temperature $\left(20 \pm 1^{\circ} \mathrm{C}\right)$ for $4 \mathrm{~h}$, which were performed under the same experimental con-

Table 1

Average composition of red mud used (wt.\%).

\begin{tabular}{lc}
\hline Constituent & $\%(\mathrm{w} / \mathrm{w})$ \\
\hline $\mathrm{SiO}_{2}$ & 18.08 \\
$\mathrm{Fe}_{2} \mathrm{O}_{3}$ & 15.30 \\
$\mathrm{Al}_{2} \mathrm{O}_{3}$ & 8.26 \\
$\mathrm{CaO}$ & 38.02 \\
$\mathrm{MgO}$ & 1.63 \\
$\mathrm{Na}_{2} \mathrm{O}$ & 3.55 \\
$\mathrm{~K}_{2} \mathrm{O}$ & 0.36 \\
$\mathrm{TiO}_{2}$ & 4.51 \\
\hline
\end{tabular}
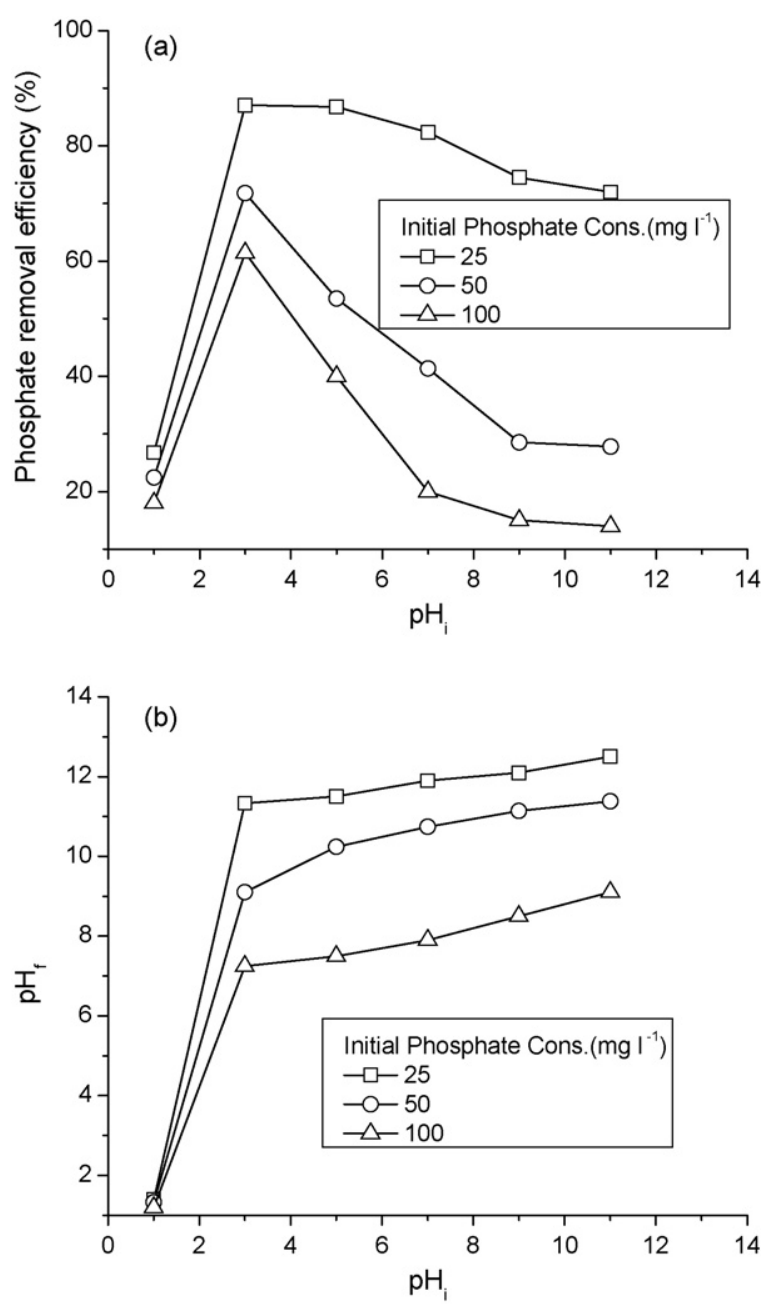

Fig. 1. Effect of initial $\mathrm{pH}$ on phosphate removal (a) and $\mathrm{pH}_{\mathrm{f}}(\mathrm{b})$ (red mud dosage: $\left.1 \mathrm{gl}^{-1}\right)$.

ditions for each factorial design experiment. The suspensions were agitated for $4 \mathrm{~h}$, sufficient time to reach equilibrium, according to previous study [5]. After equilibrium, the samples were centrifuged and the supernatants were analyzed for phosphate. $\mathrm{The}_{\mathrm{pH}}$ of the solution was also measured.

The red mud before and after adsorption were identified by Xray diffraction (XRD). The analysis was performed in a Rikaku TTRIII diffractometer at room temperature, with $\mathrm{Cu} \mathrm{K \alpha}$ radiation at a scan speed range of $0.2^{\circ} \mathrm{S}^{-1}$. The XRD patterns were recorded in the $2 \theta$ range of $10-90^{\circ}$.

\section{Results and discussion}

\subsection{The effect of initial $\mathrm{pH}$ on phosphate removal}

For the removal of phosphates from aqueous solutions by adsorption, $\mathrm{pH}$ is considered to be an important parameter. Solutions containing $1.5 \mathrm{gl}^{-1}$ red mud were adjusted to various $\mathrm{pH}$ values ranging from 1.0 to 11.0. Effect of $\mathrm{pH}_{\mathrm{i}}$ on the phosphate removal percentage and $\mathrm{pH}_{\mathrm{f}}$ is shown in Fig. 1(a) and (b). As seen from Fig. 1, the removal of phosphate strictly increases as the $\mathrm{pH}_{\mathrm{i}}$ increases up to 3.0 and thereafter, a decrease is observed. Maximum phosphate removal occurs at $\mathrm{pH}_{\mathrm{i}}$ of 3.0. It was observed that $\mathrm{pH}_{\mathrm{f}}$ values of the solution at $\mathrm{pH}_{\mathrm{i}} 3.0$ were measured as 11.3, 9.1 , and 7.3 , respectively with corresponding percentages of phos- 
Table 2

Remaining $\mathrm{Ca}^{2+}$ concentrations $\left(\mathrm{mg} \mathrm{l}^{-1}\right)$ in solution and phosphate removal efficiency (\%) after equilibrium for $50 \mathrm{mg} \mathrm{l}^{-1}$ phosphate concentration.

\begin{tabular}{|c|c|c|c|c|c|c|c|c|c|c|c|c|}
\hline \multirow[t]{3}{*}{$\mathrm{pH}_{\mathrm{i}}$} & \multicolumn{12}{|c|}{ Red mud dosage $\left(\mathrm{gl}^{-1}\right)$} \\
\hline & \multicolumn{3}{|l|}{0.25} & \multicolumn{3}{|l|}{0.5} & \multicolumn{3}{|l|}{1.0} & \multicolumn{3}{|l|}{3.0} \\
\hline & $\mathrm{Ca}^{2+}$ & $\mathrm{pH}_{\mathrm{f}}$ & Removal efficiency & $\mathrm{Ca}^{2+}$ & $\mathrm{pH}_{\mathrm{f}}$ & Removal efficiency & $\mathrm{Ca}^{2+}$ & $\mathrm{pH}_{\mathrm{f}}$ & Removal efficiency & $\mathrm{Ca}^{2+}$ & $\mathrm{pH}_{\mathrm{f}}$ & Removal efficiency \\
\hline 1.0 & 57.9 & 1.2 & 5.2 & 131.3 & 1.3 & 10.4 & 227.1 & 1.3 & 22.5 & 308.7 & 5.4 & 43.6 \\
\hline 3.0 & 45.9 & 7.0 & 12.8 & 43.5 & 7.8 & 30.5 & 31.8 & 9.1 & 71.8 & 38.1 & 10.9 & 78.3 \\
\hline 5.0 & 21.2 & 8.5 & 6.5 & 18.9 & 9.9 & 17.5 & 13.8 & 10.2 & 53.5 & 8.0 & 11.2 & 64.9 \\
\hline
\end{tabular}

phate removal of $87.1,71.8$, and $61.4 \%$ for 25,50 and $100 \mathrm{mg} \mathrm{l}^{-1}$ of phosphate concentrations.

$\mathrm{PH}$ is an important factor regarding the amount of $\mathrm{CaO}$ in the red mud, especially in a strongly acid medium due to the high concentration of hydrogen ions [35]. The effect of $\mathrm{pH}_{\mathrm{i}}$ on $\mathrm{Ca}^{2+}$ concentrations remaining in the solution and phosphate removal efficiency is given in Table 2. This table shows that $\mathrm{Ca}^{2+}$ concentrations in the solution at different red mud dosages decrease with the $\mathrm{pH}_{\mathrm{i}}$ increasing. High $\mathrm{Ca}^{2+}$ amount is released into the solution at $\mathrm{pH}_{\mathrm{i}} 1.0$, but the $\mathrm{pH}_{\mathrm{f}}$ may be too low to form insoluble phosphate compounds because of low $\mathrm{pH}_{\mathrm{i}}$. The $\mathrm{pH}_{\mathrm{f}}$ is high enough to form the insoluble phosphate compound at $\mathrm{pH}_{\mathrm{i}} 5.0$, but $\mathrm{Ca}^{2+}$ amount released into the solution is low and so phosphate removal efficiency is lower since $\mathrm{Ca}^{2+}$ in the solution is inadequate. Consequently, highest phosphate removal efficiency was achieved at $\mathrm{pH}_{\mathrm{i}}$ 3.0.

As seen from Fig. 2, the red mud before and after reaction have been checked by XRD and the XRD results showed that phosphate precipitates with calcium as apatite. The $\mathrm{Fe}_{2} \mathrm{O}_{3}$ in red mud may be an important factor for phosphate removal (as iron phosphate). However, the red mud contained more $\mathrm{CaO}(38.02 \%)$ than $\mathrm{Fe}_{2} \mathrm{O}_{3}$ (15.30\%) in this paper, $\mathrm{CaO}$ in the red mud play major role on phosphate removal. In addition, the paper mainly explains the mechanism of phosphate removal using red mud by phosphate precipitates with calcium as apatite. So the paper does not take a consideration of $\mathrm{Fe}_{2} \mathrm{O}_{3}$ in red mud for phosphate removal.

\subsection{The effect of adsorbent dosage}

The effect of red mud dosage on the removal of the phosphate from aqueous solution at $\mathrm{pH}_{\mathrm{i}} 3.0$ is shown in Fig. 3.

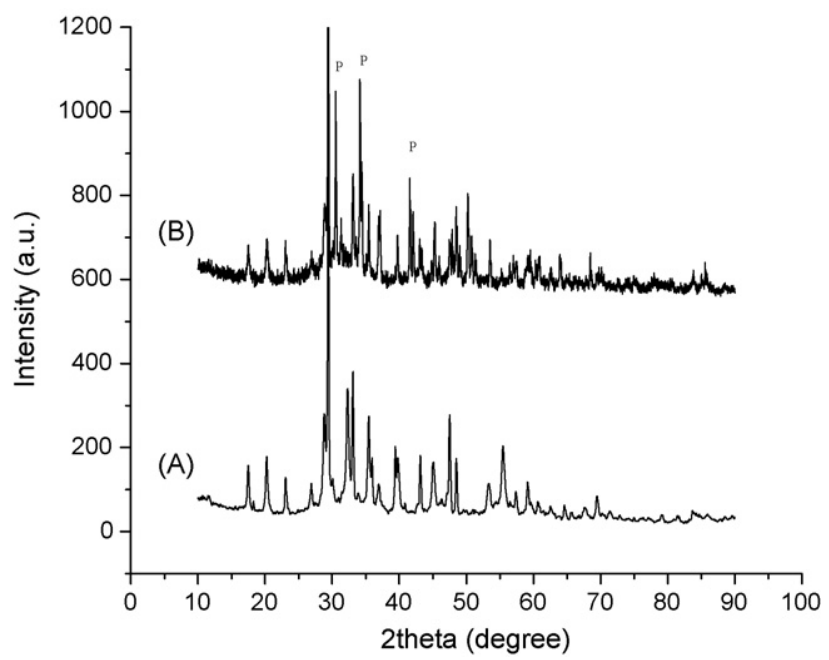

Fig. 2. X-ray diffraction patterns of the red mud (A) before adsorption and (B) after adsorption. Phosphate precipitates with calcium are marked by $(\mathrm{P})$.

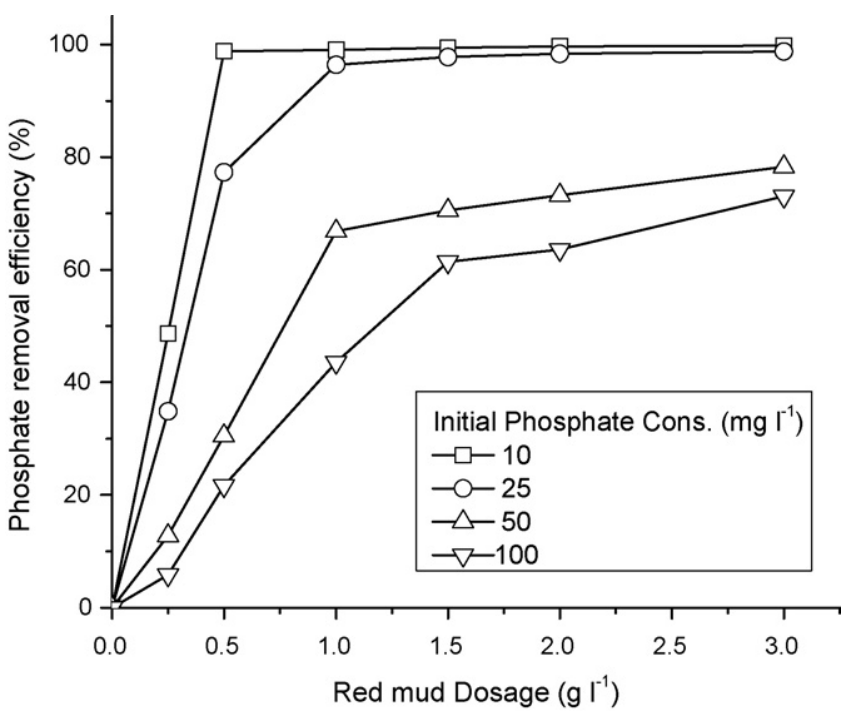

Fig. 3. Effect of red mud dosage on phosphate removal $\left(\mathrm{pH}_{\mathrm{i}} 3.0\right)$.

Initial phosphate concentrations were varied from 10 to $100 \mathrm{mgl}^{-1}$. It is apparent that the phosphate removal efficiency increases with increasing the red mud dosage for a given initial phosphate concentration. As initial phosphate concentration increases, more red mud is needed to add water in order to increase the $\mathrm{pH}_{\mathrm{f}}$ that is suitable for the formation of the insoluble phosphate compounds. The $\mathrm{pH}_{\mathrm{f}}$ values decrease with increasing phosphate concentration for a given red mud dosage. The change of orthophosphate compounds with $\mathrm{pH}$ can explain this. $\mathrm{H}_{3} \mathrm{PO}_{4}$ and $\mathrm{H}_{2} \mathrm{PO}_{4}{ }^{-}$are the predominant aqueous species at $\mathrm{pH}$ 3.0. $\mathrm{HPO}_{4}{ }^{2-}$ and $\mathrm{PO}_{4}{ }^{3-}$ may also be present at the same $\mathrm{pH}$ but

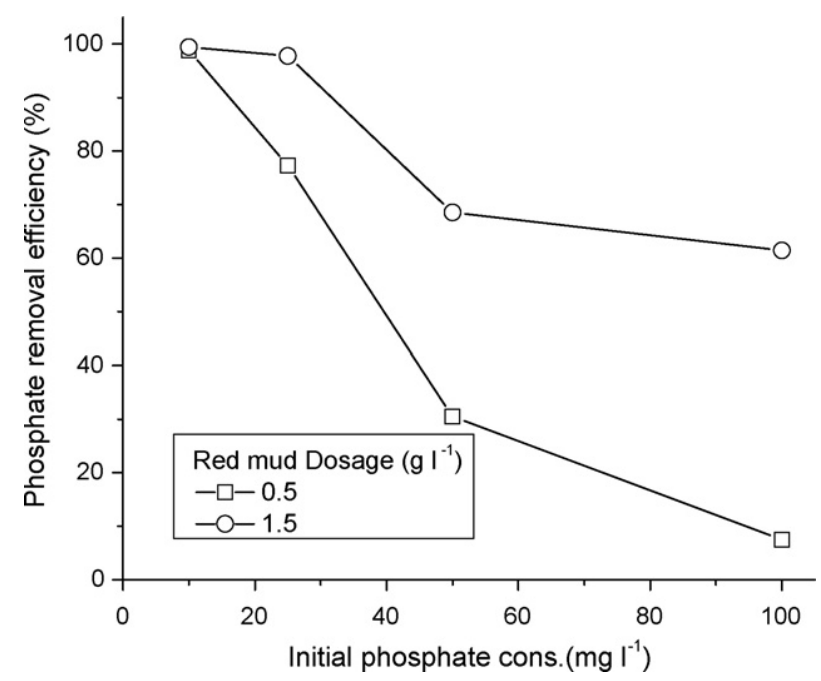

Fig. 4. Effect of initial phosphate concentration on phosphate removal $\left(\mathrm{pH}_{\mathrm{i}} 3.0\right)$. 

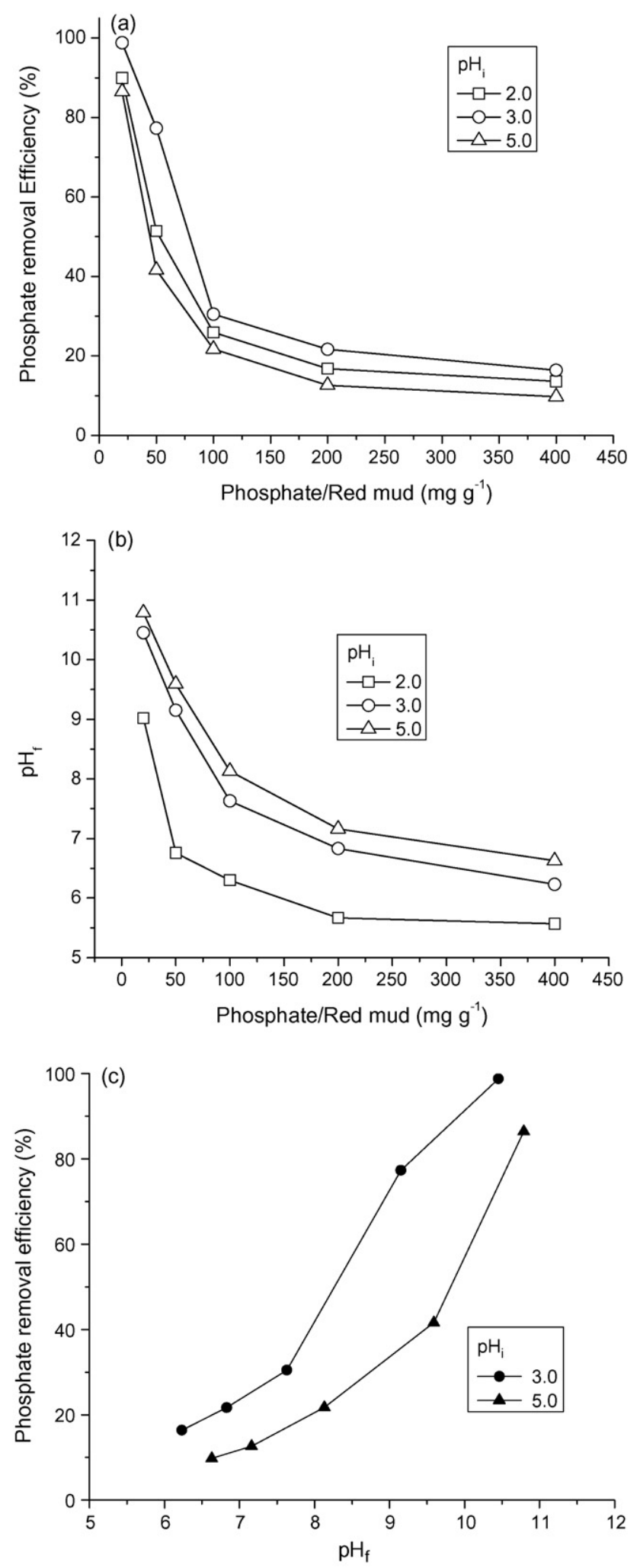

Fig. 5. Effect of phosphate/red mud ratios on phosphate removal (a) and $\mathrm{pH}_{\mathrm{f}}(\mathrm{b})$ and the relationship between final $\mathrm{pH}$ and removal efficiency (c). typically at concentrations less than $\mathrm{H}_{3} \mathrm{PO}_{4}$ and $\mathrm{H}_{2} \mathrm{PO}_{4}{ }^{-}$. The red mud does not make the $\mathrm{pH}$ of the solution increase too much for the conversion of acidic phosphate compounds use the alkaline property of red mud. Therefore, more red mud is needed to increase $\mathrm{pH}$ to an adequate value for satisfactory phosphate removal.

\subsection{The effect of initial phosphate concentration}

Fig. 4 gives phosphate removal efficiency of red mud as a function of phosphate concentration at $\mathrm{pH}_{\mathrm{i}}$ 3.0. As shown in Fig. 4, the phosphate removal efficiency decreases with increasing initial phosphate concentration for a given red mud dosage. This result is anticipated due to buffering properties of phosphate compound and insufficient calcium ions in the solution as discussed in the previous section.

\subsection{The effect of phosphate/red mud ratios}

From the previous section, it was found that red mud dosage and initial phosphate concentration have a consideration effect on the phosphate removal. So, red mud dosage and initial phosphate concentration should be considered together to study the effect of them on the phosphate removal. The effect of phosphate/red mud ratios on phosphate removal and $\mathrm{pH}_{\mathrm{f}}$ is shown in Fig. 5(a) and (b), respectively. The relationship between final $\mathrm{pH}$ and removal efficiency is shown in Fig. 5(c). As seen from Fig. 5(b), $\mathrm{pH}_{\mathrm{f}}$ has strictly reduced with increasing phosphate/red mud ratios. As discussed previously, an adequate amount of calcium ions and $\mathrm{pH}$ higher than 9 are needed to supply for adequate phosphate removal. So phosphate removal efficiency is decreased due to low calcium ions and $\mathrm{pH}_{\mathrm{f}}$. It was found that $\mathrm{pH} 9$ was a critical value to form hydroxyapatites [33]. As $\mathrm{Ca}^{2+}$ amount decreases at higher phosphate/red mud rates than 20 , phosphate removal efficiency decreases. More red mud must be added to water for satisfactory phosphate removal under the condition of high phosphate and low $\mathrm{pH}_{\mathrm{i}}$.

\subsection{Factorial design evaluation}

A $2^{3}$ full factorial design (three factors each, at two levels) was employed to evaluate the importance and interactions of the $\mathrm{pH}_{\mathrm{i}}$, red mud dosage and initial phosphate concentration. The response variables in this study are the removal efficiency of phosphate and $\mathrm{pH}_{\mathrm{f}}$. Notation that the factors used in this work have never been investigated simultaneously using factorial designs, and they were chosen for their roles, as determined previously using onevariable-at-a-time experimental procedures. All factorial designs were executed in random order to correctly evaluate experimental errors. The matrix of three variables is varied at two levels $(+1$, $-1)$. The higher level of variable was designed as'+' and the lower level was designed as '-'. For ease of notation, the effects were designed as in Table 3 which shows the values of the factors selected in this study. This factorial design results in eight tests with all possible combinations of $A, B$ and $C$. Phosphate removal efficiency $\left(Y_{1}\right)$ and $\mathrm{pH}_{\mathrm{f}}\left(Y_{2}\right)$ were measured for each of these tests as shown in Table 4.

Table 3

Factors and levels used in the $2^{3}$ factorial design study.

\begin{tabular}{lll}
\hline Factor & Low level $(-1)$ & High level $(+1)$ \\
\hline Phosphate concentration, $A\left(\mathrm{mgl}^{-1}\right)$ & 25 & 50 \\
Red mud dosage, $B\left(\mathrm{gl}^{-1}\right)$ & 0.25 & 1.5 \\
$\mathrm{pH}_{\mathrm{i}}, C$ & 3.0 & 7.0 \\
\hline
\end{tabular}


Table 4

Experimental design matrix and results for the phosphate removal efficiency and $\mathrm{pH}_{\mathrm{f}}$.

\begin{tabular}{|c|c|c|c|c|c|}
\hline \multirow[t]{2}{*}{ Run number } & \multicolumn{3}{|c|}{ Factor } & \multirow[t]{2}{*}{$Y_{1}$} & \multirow[t]{2}{*}{$Y_{2}$} \\
\hline & $A$ & B & C & & \\
\hline 1 & -1 & -1 & -1 & 15.2 & 7.4 \\
\hline 2 & 1 & -1 & -1 & 8.8 & 6.9 \\
\hline 3 & -1 & 1 & -1 & 97.6 & 10.9 \\
\hline 4 & 1 & 1 & -1 & 65.0 & 8.9 \\
\hline 5 & -1 & -1 & 1 & 6.0 & 9.5 \\
\hline 6 & 1 & -1 & 1 & 3.0 & 7.8 \\
\hline 7 & -1 & 1 & 1 & 90.1 & 12.0 \\
\hline 8 & 1 & 1 & 1 & 55.0 & 10.6 \\
\hline
\end{tabular}

A first-order model with interaction terms was chosen to fit the experimental data in Table 4:

$Y=b_{0}+b_{1} A+b_{2} B+b_{3} C+b_{12} A B+b_{123} A B C$

where $Y=$ predicted response, $b_{i}=$ coefficients, $A=$ phosphate concentration $\left(\mathrm{mgl}^{-1}\right), B=$ red mud dosage $\left(\mathrm{gl}^{-1}\right)$ and $C=\mathrm{pH}_{\mathrm{i}}$. The statistical calculations ( $t$-test, $F$-test, analysis of variance (ANOVA) and multiple regressions) were performed using Microsoft Excel. Regression analysis was performed to fit the response function ( phosphate removal efficiency and $\mathrm{pH}_{\mathrm{f}}$ ) with the experimental data (Table 5).

The mathematical models representing phosphate removal efficiency $\left(Y_{1}\right)$ and $\mathrm{pH}_{\mathrm{f}}\left(Y_{2}\right)$ in the experimental region studied can be expressed by Eqs. (2) and (3), respectively. Table 6 shows the analysis of variance for the models used to estimate phosphate removal efficiency and $\mathrm{pH}_{\mathrm{f}}$ as a function of phosphate concentration, red mud dosage and $\mathrm{pH}_{\mathrm{i}}$. The regressions are all statistically significant at the $95 \%$ confidence level. The models representing phosphate removal efficiency $\left(Y_{1}\right)$ and $\mathrm{pH}_{\mathrm{f}}\left(Y_{2}\right)$ presented high determination coefficients $\left(R^{2}=0.999,0.998\right)$ explaining 99.9 and $99.8 \%$ of

Table 5

Results of regression analysis for phosphate removal efficiency $\left(Y_{1}\right)$ and $\mathrm{pH}_{\mathrm{f}}\left(Y_{2}\right)$.

\begin{tabular}{cccl}
\hline & Coefficient & Significance effect & $t$-value \\
\hline $\begin{array}{c}\text { Phosphate removal efficiency }\left(Y_{1}\right) \\
\text { Intercept }\end{array}$ & 42.595 & 0.230489 & \\
$A$ & -9.645 & 0.230489 & - \\
$B$ & 34.335 & 0.230489 & 148.8459 \\
$C$ & -4.065 & 0.230489 & -17.6364 \\
$A B$ & -7.285 & 0.230489 & -31.6068 \\
$A B C$ & -0.745 & 0.230489 & -3.23226 \\
$\mathrm{pH}_{\mathrm{f}}\left(Y_{2}\right)$ & & & \\
Intercept & 9.2575 & 0.057581 & -12.1567 \\
$A$ & -0.7 & 0.057581 & 23.40163 \\
$B$ & 1.3475 & 0.057581 & 12.76452 \\
$C$ & 0.735 & 0.057581 & -2.43134 \\
$A B$ & -0.14 & 0.057581 & 4.037758 \\
$A B C$ & 0.2325 & 0.057581 &
\end{tabular}

Table 6

Regression analysis for phosphate removal efficiency and $\mathrm{pH}_{\mathrm{f}}$ by first-order model fitting (ANOVA)

\begin{tabular}{|c|c|c|c|c|}
\hline Source & d.f. & Sum of squares & Mean square & F-value \\
\hline \multicolumn{5}{|c|}{ Phosphate removal efficiency $\left(Y_{1}\right)$} \\
\hline Model & 5 & 10736.55 & 2147.31 & 5052.494 \\
\hline Residual & 2 & 0.85 & 0.425 & \\
\hline Core total & 7 & 10737.4 & & \\
\hline \multicolumn{5}{|l|}{$\mathrm{pH}_{\mathrm{f}}\left(Y_{2}\right)$} \\
\hline Model & 5 & 23.3571 & 4.67142 & 176.1139 \\
\hline Residual & 2 & 0.05305 & 0.026525 & \\
\hline Core total & 7 & 23.41015 & & \\
\hline
\end{tabular}

the variability in the response, respectively. This is the proof that the models describe well, the region studied:

$$
\begin{aligned}
& Y_{1}=42.595-9.645 A+34.335 B-4.065 C-7.285 A B-0.745 A B C \\
& Y_{2}=9.2575-0.7 A+1.3475 B+0.735 C-0.14 A B+0.2325 A B C
\end{aligned}
$$

The factorial design results show that red mud dosage had the strongest effect on phosphate removal efficiency and $\mathrm{pH}_{\mathrm{f}}$. Increasing red mud dosage increases phosphate removal efficiency and $\mathrm{pH}_{\mathrm{f}}$. The $b_{2}$ coefficient is the largest positive coefficient for all the model equations (see Eqs. (2) and (3)). It is known that the larger the coefficient, the larger is the effect of related parameter. The positive sign also shows that there is a direct relation between the


Fig. 6. Interaction effect of phosphate concentration and red mud dosage (a) and red mud dosage and $\mathrm{pH}_{\mathrm{i}}$ (b) for phosphate removal efficiency. The balls represent a certain weight for the response variable and the values are the average of the response variables. 

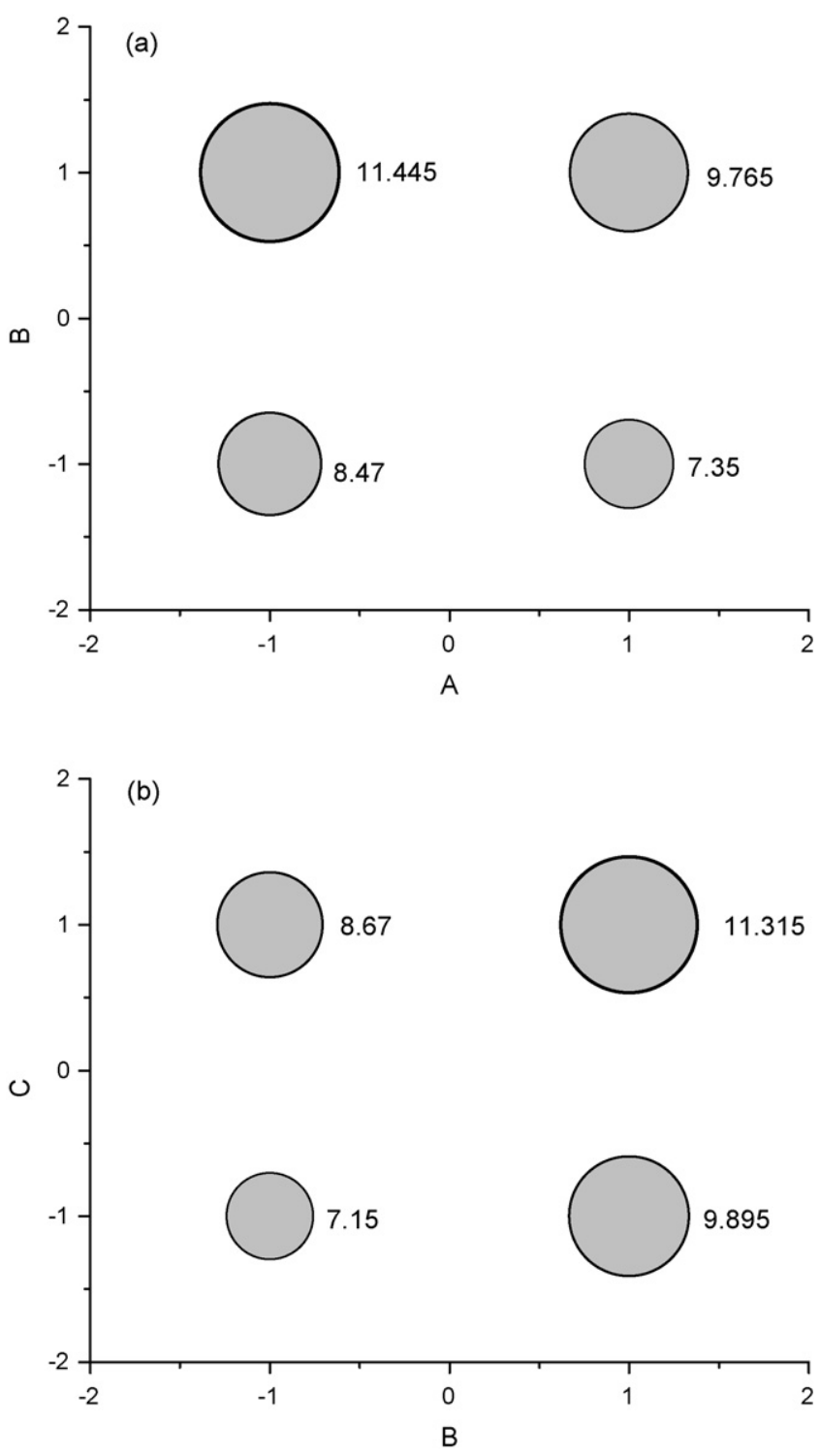

Fig. 7. Interaction effect of phosphate concentration and red mud dosage (a) and red mud dosage and $\mathrm{pH}_{\mathrm{i}}$ (b) for $\mathrm{pH}_{\mathrm{f}}$. The balls represent a certain weight for the response variable and the values are the average of the response variables.

parameter and dependent variable. The $b_{1}$ coefficient is the largest negative coefficient for $Y_{1}$ and $Y_{2}$. Increasing phosphate concentration decreases phosphate removal efficiency and $\mathrm{pH}_{\mathrm{f}}$ and its increase decreases the removal rates due to low $\mathrm{pH}$ as shown in Fig. 3.

Eqs. (2) and (3) are also seen that two-variable or three-variable interactions are significant. Evidence of large negative $(A B)$ and positive $(A B C)$ interactions is very strong and therefore cannot be ignored from the model. Figs. 6 and 7 illustrate the possible positive and negative two-variable interactions among the variables $A, B, C$ for $Y_{1}$ and $Y_{2}$. These results support the findings related to the effect of phosphate/red mud dosage ratios in Section 3.4. Because it has been found that the lower phosphate/red mud ratios, the higher removal rates, i.e., low phosphate and high red mud dosage.

The maximum removal efficiency of phosphate and $\mathrm{pH}_{\mathrm{f}}$ was found to be $97.6 \%$ and 10.89 with optimal reaction conditions initial phosphate concentration $25 \mathrm{mg} \mathrm{l}^{-1}$, red mud dosage $1.5 \mathrm{gl}^{-1}$, and $\mathrm{pH}_{\mathrm{i}}$ 3.0.

\section{Conclusion}

The results of this study indicate red mud is an effective adsorbent for the removal of phosphate in aqueous solutions. Phosphate removal efficiency of the red mud increases with increasing red mud dosage at initial pH 3.0. It was thought that adequate amount of calcium ions and higher final $\mathrm{pH}$ than 9 are ideal conditions for maximum phosphate removal. As the result of this study, red mud dosage was found to have the most positive influence on the removal efficiency of phosphate and $\mathrm{pH}_{\mathrm{f}}$. For phosphate concentration, this factor has a negative influence. The $\mathrm{pH}_{\mathrm{i}}$ has a negative effect for the removal efficiency of phosphate and positive for $\mathrm{pH}_{\mathrm{f}}$. The interaction between phosphate concentration and red mud dosage was significant for the removal efficiency of phosphate and $\mathrm{pH}_{\mathrm{f}}$.

\section{Acknowledgements}

The research work was financially supported by National Key Technology R\&D Program (2006BAJ08B00), National High Technology R\&D Program (863) from Ministry of Science \& Technology of China (2007AA06Z344) and Public Industry Research for National Environmental Protection (200709037). The authors thank Research Institute of Shandong Aluminium Co. Ltd., for providing the red mud. Thanks are due to the editors and anonymous reviewers for their helpful suggestions and enlightening comments.

\section{References}

[1] B.E. Rittmann, P.L. McCarty, Environmental Biotechnology: Principles and Applications, McGraw-Hill, Singapore, 2001.

[2] H.S. Altundogan, F. Tumen, Removal of phosphates from aqueous solutions by using bauxite. I. Effect of $\mathrm{pH}$ on the adsorption of various phosphates, J. Chem. Technol. Biotechnol. 77 (2002) 77-85.

[3] H.S. Altundogan, F. Tumen, Removal of phosphates from aqueous solutions by using bauxite. II. The activation study, J. Chem. Technol. Biotechnol. 78 (2003) 824-833.

[4] D. Mulkerrins, A.D.W. Dobson, E. Colleran, Parameters affecting biological phosphate removal from wastewaters, Environ. Int. 2 (30) (2004) 249-259.

[5] Y. Li, C. Liu, Z. Luan, X. Peng, C. Zhu, Z. Chen, Z. Zhang, J. Fan, Z. Jiaz, Phosphate removal from aqueous solutions using raw and activated red mud and fly ash, J. Hazard. Mater. B 137 (2006) 374-383.

[6] K. Karageorgiou, M. Paschalis, G.N. Anastassakis, Removal of phosphate species from solution by adsorption onto calcite used as natural adsorbent, J. Hazard. Mater. A 139 (2007) 447-452.

[7] R. Tsitouridou, J.A. Georgiou, A contribution to the study of phosphate sorption by three Greek fly ashes, Toxicol. Environ. Chem. 17 (1987) 129-138.

[8] E. Galarnaeau, R. Gehr, Phosphorus removal from wastewaters: experimental and theoretical support for alternative mechanisms, Water Res. 31 (1997) 328-338.

[9] W.P. Tang, O. Shima, A. Ookubo, K. Ooi, A kinetic study of phosphate adsorption by boehmite, J. Pharm. Sci. 86 (1997) 230-235.

[10] B.B. Johnson, A.V. Ivanov, O.N. Antzutkin, W. Forsling, ${ }^{31} \mathrm{P}$ nuclear magnetic resonance study of the adsorption of phosphate and phenyl phosphates on $\gamma-\mathrm{Al}_{2} \mathrm{O}_{3}$, Langmuir 18 (2002) 1104-1111.

[11] Z. Hongshao, R. Stanforth, Competitive adsorption of phosphate and arsenate on goethite, Environ. Sci. Technol. 35 (2001) 4753-4757.

[12] S.H. Lin, H.C. Kao, C.H. Cheng, R.S. Juang, An EXFAS study of the structures of copper and phosphate sorbed onto goethite, Colloids Surf. A 234 (2004) 71-75.

[13] R.S. Juang, J.Y. Chung, Equilibrium sorption of heavy metals and phosphate from single- and binary-sorbate solutions on goethite, J. Colloid Interf. Sci. 275(2004) 53-60.

[14] X. Huang, Intersection of isotherms for phosphate adsorption on hematite, J. Colloid Interf. Sci. 271 (2004) 296-307.

[15] N.M. Agyei, C.A. Strydom, J.H. Potgieter, An investigation of phosphate ion adsorption from aqueous solution by fly ash and slag. Cement Concrete Res. 30 (2000) 823-826.

[16] E. Oguz, Thermodynamic and kinetic investigations of $\mathrm{PO}_{4}{ }^{3-}$ adsorption on blast furnace slag, J. Colloid Interf. Sci. 281 (2005) 62-67.

[17] H. Yamada, M. Kayama, K. Saito, M. Kara, A fundamental research on phosphate removal by using slag, Water Res. 20 (1986) 547-557.

[18] G. Akay, B. Keskinler, A. Cakici, U. Danis, Phosphate removal from water by red mud using crossflow microfiltration, Water Res. 32 (3) (1998) 717-726.

[19] B. Koumanova, M. Drame, M. Pogangelova, Phosphate removal from aqueous solutions using red mud wasted in bauxite Bayer's process, Resour. Conserv. Recy. 19 (1997) 11-20. 
[20] E.W. Shin, J.S. Han, M. Jang, S.H. Min, J.K. Park, R.M. Rowell, Phosphate adsorption on aluminum-impregnated mesoporous silicates: surface structure and behavior of adsorbents, Environ. Sci. Technol. 38 (2004) 912-917.

[21] T. Kasama, Y. Watanabe, H. Yamada, T. Murakami, Sorption of phosphates on Al-pillared smectites and mica at acidic to neutral pH, Appl. Clay Sci. 25 (2004) 167-177.

[22] D.S. Bhargava, S.B. Sheldarkar, Use of TNSAC in phosphate adsorption studies and relationships, literature, experimental methodology, justification and effects of process variables, Water Res. 27 (1993) 303-312.

[23] E. Oguz, A. Gürses, N. Canpolat, Removal of phosphate from wastewaters, Cement Concrete Res. 33 (8) (2003) 1109-1112.

[24] E. Poulin, J.F. Blais, G. Mercier, Transformation of red mud from aluminium industry into a coagulant for wastewater treatment, Hydrometallurgy $92(1-2)$ (2008) 16-25.

[25] S.W. Zhang, C.J. Liu, Z.K. Luan, X.J. Peng, Arsenate removal from aqueous solutions using modified red mud, J. Hazard. Mater. 152 (2) (2008) 486-492.

[26] Y. Çengeloglu, E. Kır, M. Ersöz, Removal of fluoride from aqueous solution by using red mud, Sep. Purif. Technol. 28 (2002) 81-86.

[27] V.K. Gupta, M. Gupta, S. Sharma, Process development for the removal of lead and chromium from aqueous solutions using red mud-an aluminium industry waste, Water Res. 35 (5) (2001) 1125-1134.
[28] J. Pradhan, S.N. Das, R.S. Thakur, Adsorption of hexavalent chromium from aqueous solution by using activated red mud, J. Colloid Interf. Sci. 217 (1) (1999) 137-141.

[29] S.B. Wang, Y. Boyjoo, A. Choueib, Z.H. Zhu, Removal of dyes from aqueous solution using fly ash and red mud, Water Res. 39 (1) (2005) 129-138.

[30] S. Wang, H.M. Ang, M.O. Tadé, Novel applications of red mud as coagulant, adsorbent and catalyst for environmentally benign processes, Chemosphere 72 (11) (2008) 1621-1635.

[31] W. Huang, S. Wang, Z. Zhu, L. Li, X. Yao, V. Rudolph, F. Haghseresht, Phosphate removal from wastewater using red mud, J. Hazard. Mater. 158(1)(2008)35-42.

[32] V. Laperche, S.J. Traina, P. Gaddam, T.J. Logan, Chemical and mineralogical characterizations of $\mathrm{Pb}$ in a contamined soil: reactions with synthetic apatite, Environ. Sci. Technol. 30 (1996) 3321-3326.

[33] E. Mavropoulos, A.M. Rossi, A.M. Costa, Studies on the mechanisms of lead immobilization by hydroxyapatite, Environ. Sci. Technol. 36 (2002) 1625-1629.

[34] E. Arnold, Standard Methods for the Examination of Water and Wastewater, 16th ed., American Public Health Association, Washington, D.C., New York, 1985, pp. 445-446.

[35] Y.C. Mevra, Y. Ergun, Phosphate removal from water by fly ash: factorial experimental design, J. Hazard. Mater. B 135 (2006) 165-170. 